\title{
Clinical Pharmacokinetics and Pharmacodynamics of Pazopanib: Towards Optimized Dosing
}

\author{
Remy B. Verheijen ${ }^{1} \cdot J_{0 s}$ H. Beijnen ${ }^{1,2} \cdot$ Jan H. M. Schellens ${ }^{2,3}$ - Alwin D. R. Huitema ${ }^{1,4}$ • \\ Neeltje Steeghs ${ }^{3}$
}

Published online: 10 February 2017

(c) The Author(s) 2017. This article is published with open access at Springerlink.com

\begin{abstract}
Pazopanib is an inhibitor of the vascular endothelial growth factor receptor, platelet-derived growth factor receptor, fibroblast growth factor receptor and stem cell receptor c-Kit, and has been approved for the treatment of renal cell carcinoma and soft tissue sarcoma. The pharmacokinetics of pazopanib are complex and are characterized by $\mathrm{pH}$-dependent solubility, large interpatient variability and low, non-linear and time-dependent bioavailability. Exposure to pazopanib is increased by both food and coadministration of ketoconazole, but drastically reduced by proton pump inhibitors. Studies have demonstrated relationships between systemic exposure to pazopanib and toxicity, such as hypertension. Furthermore, a strong relationship between pazopanib trough level $\geq 20 \mathrm{mg} / \mathrm{L}$ and both tumor shrinkage and progression-free survival has been established. At the currently approved daily dose of $800 \mathrm{mg}$, approximately $20 \%$ of patients do not reach this threshold and may be at risk of suboptimal treatment. As a result of this, clinical trials have explored individualized pazopanib dosing, which demonstrate the safety and feasibility of individualized pazopanib dosing
\end{abstract}

Remy B. Verheijen

r.verheijen@nki.nl

1 Department of Pharmacy and Pharmacology, The

Netherlands Cancer Institute-Antoni van Leeuwenhoek,

Louwesweg 6, 1066 EC Amsterdam, The Netherlands

2 Department of Pharmaceutical Sciences, Utrecht University, Utrecht, The Netherlands

3 Department of Medical Oncology and Clinical Pharmacology, The Netherlands Cancer Institute-Antoni van Leeuwenhoek, Amsterdam, The Netherlands

4 Department of Clinical Pharmacy, Utrecht University Medical Center, Utrecht, The Netherlands based on trough levels. In summary, we provide an overview of the complex pharmacokinetic and pharmacodynamic profiles of pazopanib and, based on the available data, we propose optimized dosing strategies.

\section{Key Points}

The pharmacokinetics of pazopanib are described by low, non-linear and time-dependent bioavailability and large interpatient variability.

A multitude of pharmacokinetic and pharmacodynamic biomarkers have been proposed for pazopanib, but only area under the concentration-time curve (AUC) and minimum concentration $\left(C_{\min }\right)$ have been studied prospectively to individualize treatment.

There are opportunities to optimize pazopanib dosing through monitoring of $C_{\min }$ and by switching to twice-daily dosing in selected patients. These strategies hold promise to optimize pazopanib dose selection and individualization and improve treatment outcomes for cancer patients.

\section{Introduction}

Pazopanib is an inhibitor of the vascular endothelial growth factor receptor (VEGFR), platelet-derived growth factor receptor (PDGFR), fibroblast growth factor receptor (FGFR) and stem cell receptor (c-Kit), and has been 
approved for the treatment of renal cell carcinoma (RCC) and soft tissue sarcoma (STS) [1-3]. In patients with locally advanced or metastatic RCC, pazopanib increased progression-free survival (PFS) from 4.2 to 9.2 months compared with placebo, with a hazard ratio (HR) of 0.46 (95\% confidence interval [CI] 0.34-0.62; $p<0.0001$ ) [2]. In the phase III trial in STS patients, PFS was 4.6 months in the pazopanib-treated group versus only 1.6 months in the placebo group, corresponding to an HR of $0.31(95 \%$ CI $0.24-0.40 ; p<0.0001)$ [3].

Treatment with pazopanib has also been explored in a range of other tumor types, such as thyroid cancer [4], gastrointestinal stromal tumors (GISTs) [5] and ovarian cancer [6]. The most common adverse events related to pazopanib include fatigue, nausea, diarrhea, hypertension, anorexia and hair depigmentation, as well as aspartate transaminase (AST) and alanine transaminase (ALT) elevations $[2,3]$.

The purpose of this review was to provide an overview of the available clinical pharmacokinetic and pharmacodynamic data for pazopanib. In addition, we describe population pharmacokinetic models that have been developed for pazopanib and the clinical trials studying adaptive dosing strategies in an effort to optimize treatment outcomes of patients treated with this drug.

\section{Physiochemical Properties and Preclinical Pharmacology}

\subsection{Physiochemical Properties}

Pazopanib is a synthetic 5-[[4-[(2,3-dimethyl-2H-indazol6-yl)methylamino]-2-pyrimidinyl]amino]-2-methyl-benzenesulfonamide and is part of the group of indazolyl pyrimidines [7] (see Fig. 1 for the chemical structure of

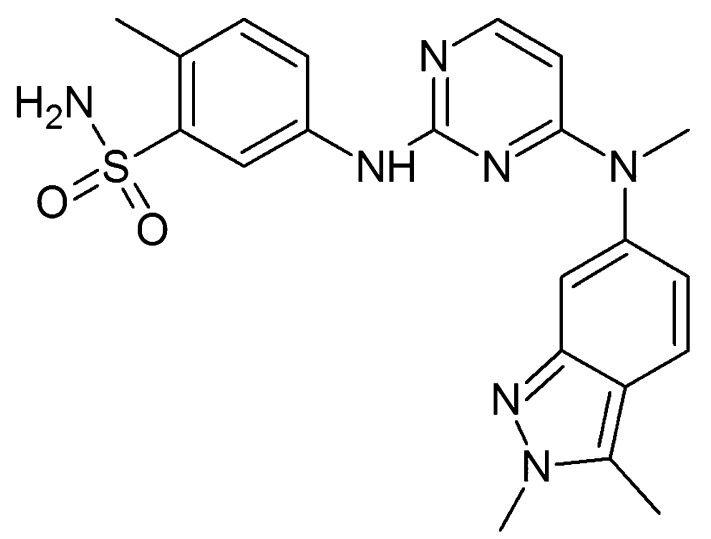

Fig. 1 Chemical structure of pazopanib [(5-[[4-[(2,3-dimethyl-2Hindazol-6-yl)methylamino]-2-pyrimidinyl]amino]-2-methylbenzenesulfonamide] pazopanib). Pazopanib has three $\mathrm{p} K_{\mathrm{a}}$ values of $2.1,6.4$, and 10.2. Commercially, it is formulated as a hydrochloride salt, which is slightly soluble at very low $\mathrm{pH}$ (1) but practically insoluble at $\mathrm{pH}$ values $\geq 4$ in aqueous matrices [8]. The permeability of pazopanib was measured in vitro by Caco- 2 monolayer experiments, with the results pointing towards dissolution rate-limited permeability. Given the above, pazopanib was classified as a class II compound, according to the Biopharmaceutics Classification System [8].

\subsection{Mechanism of Action and Preclinical Pharmacology}

Angiogenesis is one of the hallmarks of cancer and is partly controlled by the vascular endothelial growth factor (VEGF) [9]. VEGF and its receptor VEGFR mediate numerous changes within the tumor vasculature, and inhibition of this pathway affects vascular function (including both flow and permeability) in addition to inhibition of further new blood vessel growth [10].

In vitro, pazopanib has shown to inhibit VEGFR1, 2 and 3 , with a half maximal inhibitory concentrations $\left(\mathrm{IC}_{50}\right)$ of 10,30 and $47 \mathrm{nM}$, respectively [7]. It has also shown affinity for other proteins such as PDGFR $\alpha$ and $\beta$ (with an $\mathrm{IC}_{50}$ of 71 and $81 \mathrm{nM}$, respectively), c-Kit $(74 \mathrm{nM})$ and FGFR1, 3 and 4 (140, 130 and $800 \mathrm{nM}$, respectively) [1]. The activity of pazopanib based on these kinase assays was further confirmed in cell-based assays where it inhibited ligand-induced autophosphorylation of VEGFR2, PDGFR $\beta$ and c-Kit in human umbilical vein endothelial cells, human foreskin fibroblasts, and NCI-H526 cells, respectively [1].

In vivo, pazopanib has been shown to have dose-dependent anti-tumor activity in a variety of tumor xenograft models based on colon, melanoma, prostate, renal, breast and lung cancer cell lines [1]. To establish the pazopanib concentration required for optimal efficacy, VEGF-induced VEGFR2 phosphorylation was assessed in mice lungs after oral doses of pazopanib, with the results indicating maximal inhibition at a concentration of approximately $40 \mu \mathrm{mol} / \mathrm{L}$, which corresponds to a steady-state $C_{\min }$ of $17.5 \mathrm{mg} / \mathrm{L}[1]$.

\section{Clinical Pharmacokinetics}

\subsection{Pharmacokinetics in Cancer Patients}

In a phase I study $(n=63)$, pazopanib doses ranging from 50 to $2000 \mathrm{mg}$ were explored [11]. Pazopanib pharmacokinetics did not increase linearly with dose. Although the highest exposure after single administration was seen at the $2000 \mathrm{mg}$ dose, steady-state exposure to pazopanib seemed 
to plateau at doses above $800 \mathrm{mg}$ [11]. Four patients experienced dose-limiting toxicities (DLTs): gastrointestinal hemorrhage, extrapyramidal involuntary movements, hypertension, and fatigue. The maximum tolerated dose (MTD) was not reached but, based on a plateau in exposure at the $800 \mathrm{mg}$ once-daily dose, this dose was selected for further clinical development.

A single $800 \mathrm{mg}$ dose $(n=10)$ resulted in a mean (coefficient of variation percentage [CV\%]) maximum concentration $\left(C_{\max }\right)$ of $19.46(176) \mathrm{mg} / \mathrm{L}$, area under the plasma concentration-time curve from zero to $24 \mathrm{~h}$ $\left(\mathrm{AUC}_{0-24}\right)$ of $275.1(203) \mathrm{mg} \mathrm{h} / \mathrm{L}$, minimum concentration $\left(C_{\min }\right)$ of $9.4(240) \mathrm{mg} / \mathrm{L}$, and time to reach $C_{\max }\left(t_{\max }\right)$ of $3 \mathrm{~h}$. Pazopanib was eliminated with a terminal elimination half-life $\left(t_{1 / 2}\right)$ of $31.1 \mathrm{~h}$, resulting in accumulation with repeated daily dosing. At steady state (day $22, n=10$ ) $C_{\max }$, $\mathrm{AUC}_{0-24}, C_{\min }$, and $t_{\max }$ were $45.1(68.8) \mathrm{mg} / \mathrm{L}, 743.3$ (76.1) $\mathrm{mg} \mathrm{h} / \mathrm{L}, 24.0$ (67.4) $\mathrm{mg} / \mathrm{L}$, and $2 \mathrm{~h}$, respectively [11].

Administration of pazopanib as a crushed tablet or oral suspension increased $C_{\max }$ by 2.09 - and 1.29 -fold, and AUC from time zero to $72 \mathrm{~h}\left(\mathrm{AUC}_{0-72}\right)$ by $1.46-$ and $1.33-$ fold, respectively [12]. Pazopanib is bound to plasma proteins to a very large extent ( $>99.9 \%)$, with an unbound fraction, on average, of $0.011 \pm 0.0013 \%$. Protein binding did not seem to be influenced by the total pazopanib plasma concentration. Pazopanib was mainly bound to albumin and, to a lesser extend, $\alpha 1$ glycoprotein or other plasma proteins [13].

The bioavailability, metabolism, and disposition of pazopanib were studied in cancer patients using ${ }^{14} \mathrm{C}$-labeled pazopanib [14]. Absolute bioavailability was determined by comparing the dose-normalized ratio of $\mathrm{AUC}_{0-24}$ on day 15 , at an $800 \mathrm{mg}$ once-daily tablet dose, with the AUC from time zero to infinity $\left(\mathrm{AUC}_{0-\mathrm{inf}}\right)$ of a $5 \mathrm{mg}$ intravenous dose. Mean bioavailability was estimated to be $21.4 \%$ (range $13.5-38.9 \%$ ) [14].

Seven metabolites were identified, M1-M7, two of which were hydroxylated metabolites, i.e. M1 (or GSK1268992) and M2 (or GSK1268997), and one of which was an $N$-demethylated metabolite, i.e. M3 (or GSK1071306). Pazopanib was also directly glucuronidated to form M4. The hydroxylated metabolites M1 and M2 were subsequently glucuronidated to form M5 and M6, respectively. Lastly, M7 was thought to be the carboxylic acid derivative of pazopanib. In total, pazopanib metabolites accounted for $\leq 10 \%$ of plasma radioactivity and the contribution to the effect of the parent compound was shown to be low, based on their low relative concentrations and in vitro potency [14].

Pazopanib was primarily excreted via feces $(82.2 \%)$, with unchanged pazopanib being the most abundant compound excreted following oral administration. Only $2.6 \%$ of radioactivity was found in urine.

\subsection{Pharmacokinetics in Special Populations}

\subsubsection{Pediatric Cancer Patients}

A phase I study was conducted in children with STS or other treatment-refractory solid tumors $(n=51)$ [15]. Pazopanib was administered as a tablet formulation at doses of $275,350,450$, and $600 \mathrm{mg} / \mathrm{m}^{2}$, and as a suspension for oral use at 160 and $225 \mathrm{mg} / \mathrm{m}^{2}$. DLTs included lipase, amylase and ALT elevations, proteinuria, hypertension, and intracranial hemorrhage (which occurred in a patient with brain metastases). The MTD was reached at $450 \mathrm{mg} / \mathrm{m}^{2}$ (for the tablet formulation). At steady state, this dose resulted in a mean $(\mathrm{CV} \%) C_{\min }$ of $23.9(13.5) \mathrm{mg} / \mathrm{L}$ [15], which was very similar to the average (CV\%) $C_{\min }$ of $24.0(67.4) \mathrm{mg} / \mathrm{L}$ observed in the adult phase I trial at $800 \mathrm{mg}$ [11].

\subsubsection{Patients with Renal Impairment}

As pazopanib was only excreted in urine to a very limited extent (2.6\%) [14], no dedicated clinical trial was performed to assess the pharmacokinetics of pazopanib in patients with impaired renal function. However, in a small cohort of end-stage renal disease (ESRD) patients, nine patients with metastatic renal cell cancer were treated with pazopanib [16]. Five patients received $800 \mathrm{mg}$ once daily and four patients received $600 \mathrm{mg}$ once daily. Two of the patients treated with $800 \mathrm{mg}$ once daily required a dose reduction to $400 \mathrm{mg}$, while all patients who started at $600 \mathrm{mg}$ once daily were reduced to $400 \mathrm{mg}$ once daily. Median time on treatment was 11.6 months [16]. Unfortunately, no pharmacokinetic data were available in this study.

Further sporadic case reports are available of patients treated with pazopanib during dialysis [17, 18]. However, no pharmacokinetic sampling in patients with severe renal impairment or those undergoing dialysis has been reported. In a population pharmacokinetic analysis, creatinine clearance (values ranging from 30 to $150 \mathrm{~mL} / \mathrm{min}$ ) did not show an effect on the clearance of pazopanib $(n=408)$ [8]. Currently, no dose adjustments are recommended for patients with a creatinine clearance $\geq 30 \mathrm{~mL} / \mathrm{min}$, but caution is advised in patients with lower clearance values [19].

\subsubsection{Patients with Hepatic Impairment}

To study the effect of hepatic impairment on the pharmacokinetics of pazopanib, a phase I study was conducted in 89 patients with solid tumors. Patients were stratified into four groups (A, normal; $\mathrm{B}$, mild; $\mathrm{C}$, moderate; and $\mathrm{D}$, severe), using the National Cancer Institute Organ Dysfunction Working Group (NCI-ODWG) categories of liver 
dysfunction [20]. Patients in the mild group tolerated $800 \mathrm{mg}$ once daily, while patients in the moderate and severe groups only tolerated $200 \mathrm{mg}$ once daily. At steady state, the $800 \mathrm{mg}$ once-daily dose led to a median (range) $C_{\min }$ and $\mathrm{AUC}_{0-24}$ of 24.0 (8.3-74.6) $\mathrm{mg} / \mathrm{L}$ and 774.2 (214.7-2034.4) $\mathrm{mg} \mathrm{h} / \mathrm{L}$ in patients with mild hepatic dysfunction $(n=12)$. The $200 \mathrm{mg}$ dose was associated with a median (range) $C_{\min }$ and $\mathrm{AUC}_{0-24}$ of $16.2(3.1-24.2) \mathrm{mg} / \mathrm{L}$ and $256.8(65.7-487.7) \mathrm{mg} \mathrm{h} / \mathrm{L}$, respectively, in patients with moderate dysfunction $(n=11)$, and 5.7 (1.5-18.4) $\mathrm{mg} / \mathrm{L}$ and 130.6 (46.9-473.2) $\mathrm{mg} \mathrm{h} / \mathrm{L}$, respectively, in patients with severe dysfunction $(n=14)$. Based on this study, a dose of $800 \mathrm{mg}$ is advised in patients with mild hepatic impairment, and a $200 \mathrm{mg}$ dose is recommended for patients with moderate hepatic impairment. Use of pazopanib is not recommended in patients with severe liver impairment [19]. Although patients with moderate impairment were shown to tolerate doses of $200 \mathrm{mg}$ once daily, it should be taken into account that the mean $C_{\min }$ value of $16.2 \mathrm{mg} / \mathrm{L}$ in these patients was below the concentrations found to be efficacious in preclinical models $(\geq 17.5 \mathrm{mg} / \mathrm{L})[1]$ and clinical trials $(\geq 20.5 \mathrm{mg} / \mathrm{L})$ [21].

\subsection{Food Effect}

In an open-label, randomized, crossover, phase I study $(n=35)$, pazopanib pharmacokinetics were investigated in a fasted state and with a high- or low-fat meal [22]. Compared with a fasted state, $\mathrm{AUC}_{0-72}$ and $C_{\max }$ increased 2.34- and 2.08-fold, respectively, with administration of a single dose of pazopanib with a high-fat meal, and 1.92and 2.10-fold, respectively, with a low-fat meal. The $t_{1 / 2}$ was not affected by either a high- or low-fat meal, and although the pharmacokinetics of metabolites were also altered, the $\mathrm{AUC}_{0-72}$ and $C_{\max }$ of the metabolites remained below $5 \%$ that of pazopanib.

Based on this study, the authors advocated that food increased pazopanib exposure, and that pazopanib should therefore be administered in a fasted state, at least $1 \mathrm{~h}$ before or $2 \mathrm{~h}$ after a meal, to reduce variability in pazopanib exposure that may be caused by the variability of food intake in cancer patients. Given the clear food effect, it has been hypothesized that the large pharmacokinetic variability of pazopanib may be partially caused by the intake of food [23], a larger fasted interval around ingestion could therefore theoretically reduce variability, however this hypothesis has not been confirmed in a clinical trial.

\subsection{Drug-Drug Interaction Studies}

Pazopanib has been studied in a range of combination regimens, including combinations with chemotherapy
[24, 25], hormonal agents [26], and other targeted therapies [27]. In general, efforts to combine tyrosine kinase inhibitors such as pazopanib with other anticancer drugs have been unsuccessful due to limited tolerability. As none of these combinations with pazopanib are currently approved by the US Food and Drug Administration (FDA) or the European Medicines Agency (EMA), only dedicated pharmacokinetic interaction studies will be discussed in detail in this review.

To study the potential of pazopanib for drug-drug interactions, a trial in patients with advanced solid tumors $(n=24)$ evaluated the effect of pazopanib on cytochrome (CYP) 450 isoforms using a cocktail of probe drugs [28]. The probes used were midazolam (CYP3A), warfarin (CYP2C9), omeprazole (CYP2C19), caffeine (CYP1A2), and dextromethorphan (CYP2D6). Pazopanib did not have a significant effect on the $\mathrm{AUC}_{0-24}$ or $C_{\max }$ of warfarin, omeprazole or caffeine. However, the $\mathrm{AUC}_{0-24}$ and $C_{\max }$ of midazolam were increased 1.3 -fold from $53 \mathrm{ng} \mathrm{h} / \mathrm{mL}$ and $21 \mathrm{ng} / \mathrm{mL}$ to $71 \mathrm{ng} \mathrm{h} / \mathrm{mL}$ and $27 \mathrm{ng} / \mathrm{mL}$, respectively, demonstrating that pazopanib is a weak inhibitor of CYP3A4. When pazopanib was coadministered with dextromethorphan, it increased the dextromethorphan/dextrorphan ratio in urine by 1.33 - to 1.64 -fold, indicating only moderate inhibition of CYP2D6. Although the inhibition of CYP3A and CYP2D6 was weak, the authors concluded that it might be necessary to closely monitor therapy when coadministrating pazopanib with CYP3A and CYP2D6 substrates with a narrow therapeutic index.

A dedicated drug-drug interaction study was performed with pazopanib and the CYP3A4 inhibitor ketoconazole [29]. In total, 21 patients were treated with pazopanib $400 \mathrm{mg}$ and ketoconazole $400 \mathrm{mg}$. After 5 days of coadministration, pazopanib $\mathrm{AUC}_{0-24}$ increased 1.66-fold and $C_{\max }$ increased 1.45-fold. The formation of metabolites was inhibited resulting in a 0.39 -fold lower AUC of GSK1268997 (M2) and 0.56-fold lower AUC of GSK1071306 (M3). GSK1268992 (M1) was less affected, with an AUC ratio of 1.06, suggesting that this metabolite is not formed through CYP3A4 metabolism [29].

Pazopanib exposure at $400 \mathrm{mg}$ once daily in combination with ketoconazole $400 \mathrm{mg}$ once daily was approximately similar to that of the pazopanib $800 \mathrm{mg}$ once-daily dose in the phase I monotherapy study [geometric mean $(95 \% \quad \mathrm{CI}) C_{\max }$ of $59.2(45.1-77.6) \mathrm{mg} / \mathrm{L}$ and 1300 (1030-1620) $\mathrm{mg} \mathrm{h} / \mathrm{L}$ versus mean (CV\%) 45.1 (68.8) $\mathrm{mg} /$ $\mathrm{L}$ and 743.3 (76.1) $\mathrm{mg} \mathrm{h} / \mathrm{L}$. Therefore, lowering the dose of pazopanib to $400 \mathrm{mg}$ is now recommended when coadministration with a strong CYP3A4 inhibitor is therapeutically necessary [19, 29].

The pharmacokinetics of pazopanib were also studied in 13 patients who were treated with pazopanib $800 \mathrm{mg}$ (once 
daily $1 \mathrm{~h}$ before or $2 \mathrm{~h}$ after breakfast) and esomeprazole $40 \mathrm{mg}$ (once daily before bedtime) for 7 days. Pazopanib exposure was markedly reduced by a proton pump inhibitor (PPI), with an AUC ratio of 0.60 and $C_{\max }$ ratio of 0.58 . Mean $C_{\text {min }}$ was also reduced from $27.2 \mathrm{mg} / \mathrm{L}$ under control conditions to $17.3 \mathrm{mg} / \mathrm{L}$. If concomitant use of a PPI is unavoidable, pazopanib should be administered when gastric $\mathrm{pH}$ is expected to be lowest (i.e. in the evening) and together with a PPI [29, 30]. Therefore, the current recommendation is to avoid the use of gastric acid-reducing agents and, if unavoidable, take pazopanib without food once daily in the evening concomitantly with a PPI [19]. If concomitant use of an H2-receptor antagonist is necessary, pazopanib could best be taken without food at least $2 \mathrm{~h}$ before or at least $10 \mathrm{~h}$ after a dose of an H2-receptor antagonist. For short-acting antacids, the interval can be shorted to at least $1 \mathrm{~h}$ before or $2 \mathrm{~h}$ after administration of an antacid [19].

\section{Clinical Pharmacodynamics}

\subsection{Pharmacodynamic Markers}

An overview of all pharmacodynamic biomarkers significantly related to the efficacy of pazopanib treatment is provided in Table 1.

\subsubsection{Pharmacodynamics in Soft Tissue Sarcoma}

Hypertension is generally considered to be a relevant biomarker for the response of angiogenesis inhibitors [31], an often-studied example of which is bevacizumab [32]. However, for pazopanib, a retrospective analysis of 337 sarcoma patients did not find any significant relationship between hypertension and PFS (HR 0.88, 95\% CI $0.64-1.23 ; p=0.467$ ) or overall survival (OS) (HR 0.76, 95\% CI 0.54-1.08; $p=0.123$ ) [33].

Cytokines and circulating angiogenic factors in serum were investigated as predictors of pazopanib efficacy and toxicity in STS patients [34]. With regard to efficacy, increased interleukin (IL)-12 and mitochondrial pyruvate carrier 3 (MPC3) levels at baseline were related to a higher probability of PFS after 12 weeks, while low ( $\leq 7000)$ soluble vascular endothelial growth factor receptor 2 (sVEGFR2) and high $(>50)$ placental growth factor (PIGF) levels were related to lower PFS after 12 weeks. Moreover, PlGF levels were also significantly related to shorter OS [34]. A full overview of all associations is provided in Table 1. Low sVEGFR2 and high PlGF levels were also related to increased grades of hypertension and elevations of thyroid-stimulating hormone [34].

\subsubsection{Pharmacodynamics in Renal cell Carcinoma}

In RCC patients, a change in blood pressure was not significantly related to PFS, although a trend toward increased PFS was seen for higher systolic blood pressure at weeks 4 and 12 ( $p=0.06$ and 0.07 , respectively) [35].

A retrospective analysis of pazopanib phase II and III trials in RCC assessed the prognostic and predictive value of plasma concentrations of cytokine and angiogenic factors [36]. Pazopanib-treated patients with high concentrations of IL-8 $(p=0.006)$, osteopontin $(p=0.0004)$, hepatocyte growth factor (HGF; $p=0.010$ ), and tissue inhibitor of metalloproteinases-1 (TIMP-1; $p=0.006$ ) had shorter PFS than those with low concentrations, while high IL-6, VEGF and E-selectin concentrations were not predictive of PFS ( $p=0.445,0.689$, and 0.844 , respectively) [36]. In the placebo-treated group, higher IL-6 and osteopontin were associated with shorter PFS, which could suggest a relationship between progression in RCC instead of a relationship with pazopanib pharmacodynamics [36].

Analysis of VEGF genotypes in RCC biopsies suggested increased benefit of pazopanib compared with sunitinib for the s833061 TT, rs2010963 CC, and rs699947 CC genotypes [37]. However, this was based on only 19 pazopanibtreated patients for which RCC nephrectomy or biopsy tissue was available.

An analysis of germline pharmacogenetic markers in peripheral blood was performed on samples of 397 patients with RCC from the pazopanib phase II and III trials. Three polymorphisms in the IL-8 gene and hypoxia-inducible factor 1A (HIF1A) showed a significant relation with PFS [38]. The response rate was significantly associated with polymorphisms in HIF1A, nuclear receptor subfamily 1, group I, member 2 (NR1I2), and VEGFA genes [38]. A complete overview of all relationships found for the genotypes and PFS and response rates is provided in Table 1.

A randomized trial comparing pazopanib with sunitinib in RCC patients found a shorter PFS for pazopanib-treated patients with a higher $(>55) \mathrm{H}$-score for programmed death ligand 1 (PD-L1) in immunohistochemical stainings of tumor biopsies (15.1 vs. 35.6 months; $p=0.03$ ) [39]. However, since a similar effect (15.3 vs. 27.8 months; $p=0.03$ ) was seen in the sunitinib arm, it seems possible that this is a prognostic marker in RCC rather than a marker specific for pazopanib pharmacodynamics.

Dynamic contrast-enhanced magnetic resonance imaging (DCE-MRI) is a modality used for imaging of tumor vasculature and angiogenesis, and DCE-MRI parameters, such as the volume transfer constant $\left(\mathrm{K}^{\text {trans }}\right)$, which reflects the perfusion rate and capillary permeability, have been related to treatment response of other VEGFR inhibitors [40]. DCE-MRI was also explored as potential biomarker 
Table 1 Biomarkers related to pazopanib treatment efficacy

\begin{tabular}{|c|c|c|c|c|c|c|}
\hline Study & Tumor type & $N$ & Matrix & Biomarker & Association & $p$ value \\
\hline \multirow[t]{9}{*}{ Sleijfer et al. [34] } & \multirow[t]{9}{*}{ STS } & \multirow[t]{9}{*}{85} & \multirow[t]{9}{*}{ Serum } & High sVEGFR2 (12 weeks) ${ }^{\mathrm{a}}$ & $\mathrm{PFS}_{12 \mathrm{wks}} \uparrow$ & 0.0039 \\
\hline & & & & Low PIGF (12 weeks) & $\mathrm{PFS}_{12 \mathrm{wks}} \uparrow$ & 0.0318 \\
\hline & & & & & $\mathrm{OS} \uparrow$ & 0.0009 \\
\hline & & & & Low IL12 p40 & $\mathrm{PFS}_{12 \mathrm{wks}} \uparrow$ & 0.0305 \\
\hline & & & & Low MPC3 & $\mathrm{PFS}_{12 \mathrm{wks}} \uparrow$ & 0.0271 \\
\hline & & & & Low HGF & $\mathrm{PFS} \uparrow$ & 0.0079 \\
\hline & & & & Low bNGF & $\mathrm{PFS} \uparrow$ & 0.0044 \\
\hline & & & & Low ILra2 & $\mathrm{OS} \uparrow$ & 0.0078 \\
\hline & & & & ICAM-1 & $\mathrm{OS} \uparrow$ & 0.0072 \\
\hline \multirow[t]{4}{*}{ Tran et al. [36] } & \multirow[t]{4}{*}{$\mathrm{RCC}$} & \multirow[t]{4}{*}{129} & \multirow[t]{4}{*}{ Plasma } & Low IL8 & $\mathrm{PFS} \uparrow$ & 0.006 \\
\hline & & & & Low HGF & $\mathrm{PFS} \uparrow$ & 0.010 \\
\hline & & & & Low TIMP-1 & $\mathrm{PFS} \uparrow$ & 0.006 \\
\hline & & & & Low osteopontin & $\mathrm{PFS} \uparrow$ & 0.0004 \\
\hline \multirow[t]{8}{*}{ Xu et al. [38] } & \multirow[t]{8}{*}{$\mathrm{RCC}$} & \multirow[t]{8}{*}{397} & \multirow[t]{8}{*}{ Whole blood } & IL8 2767A>T & PFS & 0.009 \\
\hline & & & & IL8 $251 \mathrm{~T}>\mathrm{A}$ & PFS & 0.01 \\
\hline & & & & HIF1A $1790 \mathrm{G}>\mathrm{A}$ & PFS & 0.03 \\
\hline & & & & & $\mathrm{RR}$ & 0.02 \\
\hline & & & & NR1I2 $25385 \mathrm{C}>\mathrm{T}$ & $\mathrm{RR}$ & 0.03 \\
\hline & & & & VEGFA 2578 A $>C$ & $\mathrm{RR}$ & 0.02 \\
\hline & & & & VEGFA $1498 \mathrm{C}>\mathrm{T}$ & $\mathrm{RR}$ & 0.02 \\
\hline & & & & VEGFA $634 \mathrm{G}>\mathrm{C}$ & $\mathrm{RR}$ & 0.03 \\
\hline Sweis et al. [41] & $\mathrm{RCC}$ & 18 & DCE-MRI & High $\mathrm{K}^{\text {trans }}$ & $\mathrm{PFS} \uparrow$ & 0.036 \\
\hline
\end{tabular}

bNGF basic nerve growth factor, DCE-MRI dynamic contrast-enhanced magnetic resonance imaging, $H G F$ hepatocyte growth factor, $H I F 1 a$ hypoxia-inducible factor 1A, ICAM-1 intercellular adhesion molecule-1, IL12 p40 interleukin 12 p 40 subunit, $I L$ interleukin, $K^{\text {trans }}$ volume transfer constant, $M P C 3$ mitochondrial pyruvate carrier 3, NR1I2 nuclear receptor subfamily 1, group I, member 2, $O S$ overall survival, $P F S$ progression-free survival, $P F S_{12 w k s}$ probability of PFS at 12 weeks, $P l G F$ placental growth factor, $R C C$ renal cell carcinoma, $R R$ response rate, STS soft tissue sarcoma, sVEGFR2 soluble vascular endothelial growth factor receptor 2, TIMP-1 tissue inhibitor of metalloproteinases-1, $V E G F A$ vascular endothelial growth factor $\mathrm{A}, \uparrow$ indicates increased

${ }^{a}$ High and low biomarker levels were defined based on the median

for PFS in a cohort of RCC patients treated with pazopanib [41]. The parameter $\mathrm{K}^{\text {trans }}$ was tested dichotomously (above or below the median of $0.472 / \mathrm{min}$ ) in a survival analysis. Patients with high $\mathrm{K}^{\text {trans }}$ values had a longer PFS in univariate analysis $(p=0.036)$. However, this was no longer significant in multivariate Cox regression, including prognostic markers and previous treatments $(p=0.83)$ [41].

It should be noted that although many of the proposed biomarkers discussed above were numerically significant at the $p<0.05$ or even $<0.01$ level, many of these associations are likely to be considered statistically negligible after correction for multiple testing, given the multitude of biomarkers, sampling times, and endpoints tested in several of these studies. Therefore, further prospective confirmation of these proposed biomarkers is necessary before treatment of patients could be guided by these markers.

\subsection{Exposure-Response Analyses}

An overview of all pharmacokinetic parameters significantly related to pazopanib treatment efficacy and toxicity is provided in Table 2. Most exposure-response studies have used $C_{\min }$ as the pharmacokinetic parameter instead of $\mathrm{AUC}_{0-24}$. However, for pazopanib, $C_{\text {min }}$ correlated significantly with $\mathrm{AUC}_{0-24}$. Interestingly, this relation was better for the concentration exactly $24 \mathrm{~h}$ after intake than the concentration just before intake of the next tablet $\left(R^{2}=0.940\right.$ vs. 0.596) [23].

In the phase I trial, five of the six RCC patients with partial response or stable disease had a steady-state $C_{\min }$ of $\geq 15 \mathrm{mg} / \mathrm{L}$, while all patients with progressive disease as best response had a $C_{\min }$ of $<15 \mathrm{mg} / \mathrm{L}$ [11]. In a retrospective analysis of 177 RCC patients, relationships between exposure and response were explored. A threshold $C_{\text {min }}$ of $\geq 20.5 \mathrm{mg} / \mathrm{L}$ was significantly related to both tumor 
Table 2 Pharmacokinetic parameters significantly related to pazopanib treatment efficacy and toxicity

\begin{tabular}{|c|c|c|c|c|c|c|c|}
\hline Relationship & $\begin{array}{l}\text { Pharmacokinetic } \\
\text { parameter }\end{array}$ & $N$ & Tumor type & Value & Association & $p$ value & References \\
\hline \multirow[t]{4}{*}{ Efficacy } & $C_{\max }$ & 36 & Thyroid cancer & $r=-0.40^{\dagger}$ & $\begin{array}{l}\text { Maximum tumor size } \\
\text { reduction } \uparrow\end{array}$ & 0.021 & {$[4]$} \\
\hline & $C_{\min }$ & 177 & Renal cancer & $\geq 20.5 \mathrm{mg} / \mathrm{L}$ threshold & $\mathrm{PFS} \uparrow$ & 0.0038 & {$[21]$} \\
\hline & $C_{\min }$ & 177 & Renal cancer & $\geq 20.5 \mathrm{mg} / \mathrm{L}$ threshold & $\begin{array}{l}\text { Maximum tumor size } \\
\text { reduction } \uparrow\end{array}$ & $<0.001$ & {$[21]$} \\
\hline & $C_{\min }{ }^{\mathrm{a}}$ & 30 & $\begin{array}{l}\text { Advanced solid } \\
\text { tumors }\end{array}$ & $\geq 20.0 \mathrm{mg} / \mathrm{L}$ threshold & $\begin{array}{l}\text { Maximum tumor size } \\
\text { reduction } \uparrow\end{array}$ & 0.01 & {$[36]$} \\
\hline \multirow[t]{4}{*}{ Toxicity } & $C_{\min }$ & 54 & Renal cancer & $r=0.95^{*}$ & Blood pressure $\uparrow$ & 0.0075 & [21] \\
\hline & $C_{\min }$ & 59 & $\begin{array}{l}\text { Pediatric advanced } \\
\text { solid tumors }\end{array}$ & $\begin{array}{c}C_{\min } 38.8 \pm 11.1 \mathrm{vs} . \\
29.6 \pm 13.6 \mathrm{mg} / \mathrm{L}\end{array}$ & Any DLT $\uparrow$ & 0.04 & {$[15]$} \\
\hline & $C_{\min }$ & 38 & $\begin{array}{l}\text { Pediatric advanced } \\
\text { solid tumors }\end{array}$ & $\begin{array}{c}C_{\min } 43.7 \pm 13.3 \text { vs. } \\
29.4 \pm 13.0 \mathrm{mg} / \mathrm{L}\end{array}$ & Blood pressure $\uparrow$ & 0.004 & {$[15]$} \\
\hline & $\mathrm{AUC}_{0-24}$ & 29 & $\begin{array}{l}\text { Pediatric advanced } \\
\text { solid tumors }\end{array}$ & $r=0.595^{*}$ & DLT cycle $1 \uparrow$ & 0.01 & [15] \\
\hline
\end{tabular}

$A U C_{0-24}$ area under the plasma concentration-time curve from zero to $24 \mathrm{~h}, C_{\max }$ maximum plasma concentration (during the first cycle), $C_{\min }$ minimum plasma concentration/trough level (at steady state), DLT dose-limiting toxicity, PFS progression-free survival, $r$ Spearman's rank correlation coefficient ${ }^{\dagger}$ or correlation coefficient ${ }^{\ddagger}, \uparrow$ indicates increased

${ }^{a}$ Mean of all available $\mathrm{C}_{\min }$ samples

shrinkage and PFS. Patients below the threshold had a median tumor shrinkage of 6.9 versus $37.9 \%$ for patients with a pazopanib $C_{\min }$ above the threshold $(p<0.001)$. PFS was also strongly associated with $C_{\min }$, with patients with a pazopanib $C_{\min }$ level $<20.5 \mathrm{mg} / \mathrm{L}$ having a PFS of only 19.6 weeks compared to 52.0 weeks for patients with a pazopanib $C_{\min }$ level $\geq 20.5 \mathrm{mg} / \mathrm{L}(p=0.0038)$.

Exposure-response relationships have also been studied in other tumor types. A post hoc subgroup analysis in a randomized phase II study of pazopanib versus best supportive care in GIST patients found a 4-month PFS of $42.5 \%$ in patients with a pazopanib $C_{\min }$ level $<20 \mathrm{mg} / \mathrm{L}$ versus $71.1 \%$ in patients with a pazopanib $C_{\min }$ level $\geq 20 \mathrm{mg} / \mathrm{L}(n=26 ; p=0.17)$ [5]. In patients with metastatic, rapidly progressive, radioiodine-refractory differentiated thyroid cancers, pazopanib $C_{\max }$ correlated with tumor response (maximum change in tumor size, $p=0.021)$ and was significantly higher in responders than in patients with no tumor response $(p=0.009)$. In a pediatric phase I trial in STS and advanced solid tumors, all but one patient with clinical benefit had a $C_{\min } \geq 20 \mathrm{mg} / \mathrm{L}$, and all five patients who received therapy for 1 year or more had a $C_{\min } \geq 30 \mathrm{mg} / \mathrm{L}$ [15].

Unfortunately, no pharmacokinetic samples were taken in the pivotal study of pazopanib in STS [3]. Therefore, the threshold of $\geq 20 \mathrm{mg} / \mathrm{L}$ was not clinically validated for STS patients. However, a trial in advanced solid tumors found a trend towards improved tumor size reduction $(-6.01$ vs. $+13.5 \% ; p=0.28)$ and PFS (47.9 vs. 11.5 weeks; $p=0.06)$ in a subset of STS patients $(n=7)$ with an average $C_{\min } \geq 20.0 \mathrm{mg} / \mathrm{L}$ [42]. The same trial found a significant relationship using the same threshold and tumor size reduction in the overall population of patients with advanced solid tumors $(-6.49$ vs. $+14.6 \%, n=30$; $p=0.01)$ [42].

In summary, multiple studies support the use of a pazopanib $C_{\min }$ of $\geq 20 \mathrm{mg} / \mathrm{L}$ as a pharmacokinetic threshold for efficacy.

\subsection{Exposure-Toxicity Analyses}

In a retrospective analysis of exposure as a predictor of toxicity in RCC patients $(n=205)$, the frequency of hypertension, diarrhea, hair color change, ALT elevations, stomatitis, and hand-foot syndrome increased with increasing pazopanib $C_{\min }$. However, other adverse events such as vomiting, fatigue, nausea, dysgeusia, and rash displayed no obvious relationship with exposure [21].

The relationship between pharmacokinetic exposure and toxicity was studied further and, interestingly, the correlation between exposure and hypertension was stronger for $C_{\text {min }}$ than for $\mathrm{AUC}_{0-24}\left(r^{2}\right.$ of $0.91[p=0.0075]$ and 0.25 [ $p=0.23$ ], respectively) [21]. In pediatric cancer patients, $C_{\min }$ was related to the occurrence of DLTs. Patients experiencing a DLT had a mean \pm standard deviation $C_{\min }$ of $38.8 \pm 11.1$ versus only $29.6 \pm 13.6 \mathrm{mg} / \mathrm{L}$ for patients who did not experience a DLT $(p=0.04)$. $C_{\min }$ was also related to grade 2 or higher hypertension. Here, $C_{\min }$ was $43.7 \pm 13.3 \mathrm{mg} / \mathrm{L}(n=11)$ in hypertensive patients compared with only $29.4 \pm 13.0 \mathrm{mg} / \mathrm{mL} \quad(n=27) \quad$ in 
normotensive patients ( $p=0.004)$. There also was a strong association between $\mathrm{AUC}_{0-24}$ and the occurrence of DLTs in cycle 1 ( $n=29 ; r=0.595 ; p=0.001)$ [15].

A randomized, double-blind, placebo-controlled trial comparing pazopanib with placebo and moxifloxacin (as a positive control) did not find an effect of pazopanib or its metabolites on the QTcF interval [43].

In the registration trials, the probability of grade 3 or higher ALT elevation has been reported to increase with higher pazopanib $C_{\min }$ [8]. However, a recent study suggested that the mechanism of this hepatotoxicity may be related to genetic mutations in the human leukocyte antigen (HLA), specifically with the HLA-B*57:01 genotype. It may therefore be the case that hepatotoxicity is mediated by an immunological reaction that would most likely be unrelated to pazopanib exposure or dose [44].

Pazopanib-related ALT elevations have also been shown to be associated with the rs2858996 and rs707889 polymorphisms in the hemochromatosis HFE gene [45]. Moreover, the risk of ALT elevations in cancer patients treated with pazopanib was shown to be higher in those patients who concomitantly used simvastatin [46].

Interestingly, case reports show that administration of a starting dose of prednisolone $30 \mathrm{mg}$ (which is subsequently slowly tapered down) is a promising treatment strategy for pazopanib-related transaminase elevations [47]. The suggestion that immunosuppressive drugs are effective in treating this form of toxicity further supports the hypothesis that this drug-induced liver injury is immunologically mediated.

\section{Population Pharmacokinetic and Pharmacodynamic Studies}

To date, several pharmacometric models have been developed for pazopanib. Two models focused on tumor growth kinetics and two focused on pharmacokinetic modeling. The first tumor growth model quantified the effect of pazopanib in clinical data from phase II $(n=220)$ and III studies ( $n=423$ ). This study quantified the tumor inhibition of pazopanib using a modified Wang model and identified prognostic markers (including prior radiotherapy, baseline tumor size, tumor shrinkage rate, and tumor regrowth rate) as predictors for the formation of new lesions [48]. The second tumor growth model used both preclinical and clinical ( $n=47$ ) data. This semi-mechanistic model also described the role of tumor vasculature (based on preclinical experiments) in tumor growth and shrinkage. This study suggested the antitumor effect of pazopanib might be comprised of two separate mechanisms - the first a direct cytotoxic effect and the second a slower antiangiogenic effect [49].

At present, two model-based pharmacokinetic studies have been reported. The first was a one-compartment model with first-order absorption and elimination-based pharmacokinetic data obtained from a phase I study of pazopanib in combination with bevacizumab $(n=15)$ [50]. Coadministration of bevacizumab did not influence pazopanib $C_{\text {min }}$. Interindividual variability in this study was quantified at $40 \%$ and an interoccasion variability at $27 \%$. However, in these 15 patients, no significant relationships were found between measures of exposure and either DLTs or treatment response (measured by Response Evaluation Criteria In Solid Tumors [RECIST] 1.1) [50].

The second population pharmacokinetic model was based on a larger data set from three clinical studies ( $n=96$ ) [51]. The pH-limited solubility of pazopanib [8] was best described by a two-phase first-order absorption [51]. To account for the non-linear bioavailability, a relative bioavailability parameter $(\mathrm{rF})$ was introduced as a function of dose $(\mathrm{rFd})$ and time $(\mathrm{rFt})$. $\mathrm{rFd}$ was set at 1 for the (lowest) $200 \mathrm{mg}$ dose and decreased in a maximum effect $\left(E_{\max }\right)$ manner. The influence of time on $\mathrm{rFt}$ was best described by a first-order decay [51].

Simulation studies were performed to quantify the effect of time on pazopanib pharmacokinetics. When comparing exposure in week 2 to week 4 , both the $C_{\min }$ and AUC dropped by $11 \%$. A decrease in exposure has also been reported for other tyrosine kinase inhibitors such as imatinib [52]; the mechanism behind this effect is unclear [53]. For pazopanib, it is hypothesized that this reduced exposure could be caused by autoinduction of CYP3A4 as it has been reported that pazopanib induces CYP3A4 in vitro through interaction with the human pregnane $X$ receptor $[8,51]$, but this theory has not yet been confirmed in clinical studies. Simulations also indicated that the nonlinear bioavailability could be leveraged to increase $C_{\min }$ in low-exposure patients by switching from a once- to twicedaily dosing regimen. At steady state, $C_{\min }$ on the $400 \mathrm{mg}$ twice-daily dose was $75 \%$ higher than on the $800 \mathrm{mg}$ oncedaily dose, i.e. $39 \mathrm{mg} / \mathrm{L}$ compared with $22 \mathrm{mg} / \mathrm{L}$, respectively. AUC increased by 59\%, from 665 to $1056 \mathrm{mg} \mathrm{h} / \mathrm{L}$, by switching from $800 \mathrm{mg}$ once daily to $400 \mathrm{mg}$ twice daily [51].

This strategy of splitting intake moments, has the advantage of increasing exposure without increasing the overall daily dose and the cost of therapy. However, future prospective clinical trials are needed to confirm this hypothesis before such a strategy can be implemented.

\section{Individualizing Pazopanib Therapy}

Several studies have identified pharmacokinetic and pharmacodynamic biomarkers for pazopanib treatment efficacy in cancer patients (Tables 1, 2). Moreover, it has been shown that at the currently approved dose of $800 \mathrm{mg}$ once 
daily, approximately $20 \%$ of patients do not reach the pharmacokinetic threshold of $C_{\min } \geq 20 \mathrm{mg} / \mathrm{L}$ and are therefore at risk of suboptimal efficacy [21]. Furthermore, intrapatient variability in pharmacokinetics (25-27\%) $[23,50]$ was markedly smaller than interpatient variability $(67-72 \%)[11,42]$.

As a result of this, two clinical trials have investigated individualized pharmacokinetically-guided dosing of pazopanib in cancer patients [23, 42]. The first was a study in advanced solid tumors $(n=13)$ which used an $\mathrm{AUC}_{0-24}$ range of $715-920 \mathrm{mg} \mathrm{h} / \mathrm{L}$ as the pharmacokinetic target and set a reduction in variability as the primary endpoint [23]. All patients were treated for three consecutive periods of 2 weeks. In the first period, all patients received pazopanib $800 \mathrm{mg}$ once daily to reach steady-state exposure; in the second period, patients either received a pharmacokinetic-guided dose or the fixed $800 \mathrm{mg}$ dose; and during the last period, the regimens were switched. In this trial, AUCguided dosing did not significantly reduce interpatient variability. Interpatient variability in $C_{\min }$ was 36.9 and $31.9 \%$ in the AUC-guided and fixed-dose arms, respectively. Overall, $53.9 \%$ of patients in the AUC-guided dosing arm and $46.2 \%$ of patients in the fixed-dosing arm achieved the target exposure. Based on these results, the authors concluded that it might be more beneficial to target the $C_{\min }$ threshold rather than an AUC range.

The second study was a prospective trial in 30 patients with advanced solid tumors. This study set $C_{\min } \geq 20.0 \mathrm{mg} /$ $\mathrm{L}$ as the target exposure [42] At weeks 3, 5, and 7, the pazopanib dose was increased if $C_{\min }$ was $<20.0 \mathrm{mg} / \mathrm{L}$. Patients with a $C_{\min }<15.0 \mathrm{mg} / \mathrm{L}$ received a dose increase of $400 \mathrm{mg}$ in the absence of grade 2 or higher toxicity, or $200 \mathrm{mg}$ when experiencing grade 2 toxicity, while patients with a $C_{\min }$ of $15.0-19.9 \mathrm{mg} / \mathrm{L}$ received a $200 \mathrm{mg}$ dose increase if toxicity was below grade 3 . No patients were treated above the prespecified limit of $2000 \mathrm{mg}$ once daily. Furthermore, the dose was reduced in cases of grade 3 or higher toxicity. This dosing algorithm led to patients being treated at dosages ranging from 400 to $1800 \mathrm{mg} /$ day. Mean $C_{\text {min }}$ in patients whose dose was successfully increased above $800 \mathrm{mg}(n=10)$ rose significantly from only 13.2 to $22.9 \mathrm{mg} / \mathrm{L}$ (above the prespecified target of $\geq 20 \mathrm{mg} / \mathrm{L}$ ). Patients with a high $C_{\min }$ who experienced grade 3 or higher toxicity $(n=9)$ and who initially required a dose reduction had a mean $C_{\text {min }}$ of $51.3 \mathrm{mg} / \mathrm{L}$, but, even after subsequent dose reductions, mean $C_{\min }$ was still above the $>20 \mathrm{mg} / \mathrm{L}$ target, at $28.2 \mathrm{mg} / \mathrm{L}$ [42]. The overall variability in $C_{\min }$ was reduced from $71.9 \%$ on the fixed-dose schedule (week 2) to $33.9 \%$ (week 8) after applying the pharmacokinetically-guided dosing algorithm.

This trial demonstrated the feasibility of individualized $C_{\text {min-guided dosing. Future prospective clinical trials to }}$ validate this dosing strategy on clinically relevant endpoints are warranted. Furthermore, given its evident exposure-response relationship, pazopanib $C_{\min }$ monitoring in routine care is already of clear importance in specific clinical situations, such as hepatic impairment [54] or coadministration of PPIs or CYP3A4 inhibitors/inducers [29].

To facilitate pharmacokinetic monitoring of pazopanib in routine care, dried blood spot sampling could be used as a less invasive alternative to venous blood sampling. Multiple validated bioanalytical assays are already available for this purpose [55, 56].

\section{Conclusions}

We have provided an overview of the complex pharmacokinetic and pharmacodynamic profile of pazopanib, and critically reviewed the published (population) pharmacokinetic and pharmacodynamic data on pazopanib in patients and special patient populations. The pharmacokinetics of pazopanib are described by low, non-linear and time-dependent bioavailability and large interpatient variability. A multitude of pharmacokinetic and pharmacodynamic biomarkers have been proposed for pazopanib, but only AUC and $C_{\min }$ have been studied prospectively to individualize treatment.

There are opportunities to optimize pazopanib dosing through monitoring of $C_{\min }$ and by switching to twice-daily dosing in selected patients. These strategies hold promise to optimize pazopanib dose selection and individualization, and improve treatment outcomes for cancer patients.

\section{Compliance with Ethical Standards}

Funding No funding was received for this research.

Conflict of interest Dr. Neeltje Steeghs received an unrestricted grant (funding and study medication) from GlaxoSmithKline as principal investigator for an investigator-initiated study of pazopanib, which, as of June 2015, is an asset of Novartis. Remy B. Verheijen, Jos H. Beijnen, Jan H.M. Schellens, and Alwin D.R. Huitema declare that they have no conflicts of interest to disclose.

Open Access This article is distributed under the terms of the Creative Commons Attribution-NonCommercial 4.0 International License (http://creativecommons.org/licenses/by-nc/4.0/), which permits any noncommercial use, distribution, and reproduction in any medium, provided you give appropriate credit to the original author(s) and the source, provide a link to the Creative Commons license, and indicate if changes were made.

\section{References}

1. Kumar R, Knick VB, Rudolph SK, Johnson JH, Crosby RM, Crouthamel M-C, et al. Pharmacokinetic-pharmacodynamic correlation from mouse to human with pazopanib, a multikinase angiogenesis inhibitor with potent antitumor and antiangiogenic activity. Mol Cancer Ther. 2007;6:2012-21. 
2. Sternberg CN, Davis ID, Mardiak J, Szczylik C, Lee E, Wagstaff $\mathrm{J}$, et al. Pazopanib in locally advanced or metastatic renal cell carcinoma: results of a randomized phase III trial. J Clin Oncol. 2010;28:1061-8.

3. van der Graaf WT, Blay JY, Chawla SP, Kim DW, Bui-Nguyen B, Casali PG, et al. Pazopanib for metastatic soft-tissue sarcoma (PALETTE): a randomised, double-blind, placebo-controlled phase 3 trial. Lancet. 2012;379:1879-86.

4. Bible KC, Suman VJ, Molina JR, Smallridge RC, Maples WJ, Menefee ME, et al. Efficacy of pazopanib in progressive, radioiodine-refractory, metastatic differentiated thyroid cancers: results of a phase 2 consortium study. Lancet Oncol. 2010;11:962-72.

5. Mir O, Cropet C, Toulmonde M, Cesne AL, Molimard M, Bompas E, et al. Pazopanib plus best supportive care versus best supportive care alone in advanced gastrointestinal stromal tumours resistant to imatinib and sunitinib (PAZOGIST): a randomised, multicentre, open-label phase 2 trial. Lancet Oncol. 2016;17:632-41.

6. du Bois A, Floquet A, Kim J-W, Rau J, del Campo JM, Friedlander $\mathrm{M}$, et al. Incorporation of pazopanib in maintenance therapy of ovarian cancer. J Clin Oncol. 2014;32:3374-82.

7. Harris P, Boloor A, Cheung M, Kumar R, Crosby RM, DavisWard RG, et al. Discovery of 5-[[4-[(2,3-dimethyl-2H-indazol-6yl)methylamino]-2-pyrimidinyl]amino]-2-methyl-benzenesulfonamide (Pazopanib), a novel and potent vascular endothelial growth factor receptor inhibitor. J Med Chem. 2008;51:4632-40.

8. US Food and Drug Administration, Center for Drug Evaluation and Research. Pazopanib clinical pharmacology and biopharmaceutics review. 2008; Available at: http://www.accessdata.fda. gov/drugsatfda_docs/nda/2009/022465s000_ClinPharmR.pdf.

9. Hanahan D, Weinberg RA. Hallmarks of cancer: the next generation. Cell. 2011;144:646-74.

10. Ellis LM, Hicklin DJ. VEGF-targeted therapy: mechanisms of anti-tumour activity. Nat Rev Cancer. 2008;8:579-91.

11. Hurwitz HI, Dowlati A, Saini S, Savage S, Suttle AB, Gibson $\mathrm{DM}$, et al. Phase I trial of pazopanib in patients with advanced cancer. Clin Cancer Res. 2009;15:4220-7.

12. Heath EI, Forman K, Malburg L, Gainer S, Suttle AB, Adams L, et al. A phase I pharmacokinetic and safety evaluation of oral pazopanib dosing administered as crushed tablet or oral suspension in patients with advanced solid tumors. Invest New Drugs. 2012;30:1566-74.

13. Imbs DC, Paludetto MN, Négrier $\mathrm{S}$, Powell H, Lafont T, WhiteKoning M, et al. Determination of unbound fraction of pazopanib in vitro and in cancer patients reveals albumin as the main binding site. Invest New Drugs. 2016;34:41-8.

14. Deng Y, Sychterz C, Suttle AB, Dar MM, Bershas D, Negash K, et al. Bioavailability, metabolism and disposition of oral pazopanib in patients with advanced cancer. Xenobiotica. 2013;43:443-53.

15. Glade Bender JL, Lee A, Reid JM, Baruchel S, Roberts T, Voss $\mathrm{SD}$, et al. Phase I pharmacokinetic and pharmacodynamic study of pazopanib in children with soft tissue sarcoma and other refractory solid tumors: a children's oncology group phase I consortium report. J Clin Oncol. 2013;31:3034-43.

16. Shetty AV, Matrana MR, Atkinson BJ, Flaherty AL, Jonasch E, Tannir NM. Outcomes of patients with metastatic renal cell carcinoma and end-stage renal disease receiving dialysis and targeted therapies: a single institution experience. Clin Genitourin Cancer. 2014;12:348-53.

17. Czarnecka AM, Kawecki M, Lian F, Korniluk J, Szczylik C. Feasibility, efficacy and safety of tyrosine kinase inhibitor treatment in hemodialyzed patients with renal cell cancer: 10 years of experience. Future Oncol. 2015;11:2267-82.
18. Bersanelli M, Facchinetti F, Tiseo M, Maiorana M, Buti S. Pazopanib in renal cell carcinoma dialysis patients: a mini-review and a case report. Curr Drug Targets. 2016;17(5):1755-60.

19. Committee for Medicinal Products for Human Use (CHMP), European Medicines Agency. Pazopanib summary of product characteristics. 2013; Available at: http://www.ema.europa.eu/ docs/en_GB/document_library/EPAR_-_Product_Information/ human/001141/WC500094272.pdf.

20. Shibata SI, Chung V, Synold TW, Longmate JA, Suttle AB, Ottesen LH, et al. Phase I study of pazopanib in patients with advanced solid tumors and hepatic dysfunction: a National Cancer Institute Organ Dysfunction Working Group study. Clin Cancer Res. 2013;19:3631-9.

21. Suttle AB, Ball H, Molimard M, Hutson T, Carpenter C, Rajagopalan D, et al. Relationships between pazopanib exposure and clinical safety and efficacy in patients with advanced renal cell carcinoma. Br J Cancer. 2014;111:1-8.

22. Heath EI, Chiorean EG, Sweeney CJ, Hodge JP, Lager JJ, Forman $\mathrm{K}$, et al. A phase I study of the pharmacokinetic and safety profiles of oral pazopanib with a high-fat or low-fat meal in patients with advanced solid tumors. Clin Pharmacol Ther. 2010;88:818-23.

23. de Wit D, van Erp NP, den Hartigh J, Wolterbeek R, den Hollandervan Deursen M, Labots M, et al. Therapeutic drug monitoring to individualize the dosing of pazopanib: a pharmacokinetic feasibility study. Ther Drug Monit. 2014;37:331-8.

24. Hamberg P, Boers-Sonderen MJ, van der Graaf WTA, de Bruijn $\mathrm{P}$, Suttle AB, Eskens FALM, et al. Pazopanib exposure decreases as a result of an ifosfamide-dependent drug-drug interaction: results of a phase I study. Br J Cancer. 2014;110:888-93.

25. Imbs DC, Diéras V, Bachelot T, Campone M, Isambert N, Joly F, et al. Pharmacokinetic interaction between pazopanib and cisplatin regimen. Cancer Chemother Pharmacol. 2016;77:385-92.

26. Sridhar SS, Joshua AM, Gregg R, Booth CM, Murray N, Golubovic J, et al. A phase II study of GW786034 (pazopanib) with or without bicalutamide in patients with castration-resistant prostate cancer. Clin Genitourin Cancer. 2015;13:124-9.

27. Monk BJ, Lopez LM, Zarba JJ, Oaknin A, Tarpin C, Termrungruanglert W, et al. Phase II, open-label study of pazopanib or lapatinib monotherapy compared with pazopanib plus lapatinib combination therapy in patients with advanced and recurrent cervical cancer. J Clin Oncol. 2010;28:3562-9.

28. Goh BC, Reddy NJ, Dandamudi UB, Laubscher KH, Peckham T, Hodge JP, et al. An evaluation of the drug interaction potential of pazopanib, an oral vascular endothelial growth factor receptor tyrosine kinase inhibitor, using a modified Cooperstown 5+1 cocktail in patients with advanced solid tumors. Clin Pharmacol Ther. 2010;88:652-9.

29. Tan AR, Gibbon DG, Stein MN, Lindquist D, Edenfield JW, Martin JC, et al. Effects of ketoconazole and esomeprazole on the pharmacokinetics of pazopanib in patients with solid tumors. Cancer Chemother Pharmacol. 2013;71:1635-43.

30. Warrington S, Baisley K, Boyce M, Tejura B, Morocutti A, Miller N. Effects of rabeprazole, $20 \mathrm{mg}$, or esomeprazole, $20 \mathrm{mg}$, on 24-h intragastric $\mathrm{pH}$ and serum gastrin in healthy subjects. Aliment Pharmacol Ther. 2002;16:1301-7.

31. Murukesh N, Dive C, Jayson GC. Biomarkers of angiogenesis and their role in the development of VEGF inhibitors. Br J Cancer. 2010;102:8-18.

32. Zhong J, Ali AN, Voloschin AD, Liu Y, Curran WJ, Crocker IR, et al. Bevacizumab-induced hypertension is a predictive marker for improved outcomes in patients with recurrent glioblastoma treated with bevacizumab. Cancer. 2015;121:1456-62.

33. Duffaud F, Sleijfer S, Litière S, Ray-Coquard I, Le Cesne A, Papai Z, et al. Hypertension (HTN) as a potential biomarker of 
efficacy in pazopanib-treated patients with advanced non-adipocytic soft tissue sarcoma. A retrospective study based on European Organisation for Research and Treatment of Cancer (EORTC) 62043 and 62072 trial. Eur J Cancer. 2015;51:2615-23.

34. Sleijfer S, Gorlia T, Lamers C, Burger H, Blay J-Y, Le Cesne A, et al. Cytokine and angiogenic factors associated with efficacy and toxicity of pazopanib in advanced soft-tissue sarcoma: an EORTC-STBSG study. Br J Cancer. 2012;107:639-45.

35. Goldstein D, Rosenberg JE, Figlin RA, Townsend RR, Mccann L, Carpenter $\mathrm{C}$, et al. Is change in blood pressure a biomarker of pazopanib and sunitinib efficacy in advanced/metastatic renal cell carcinoma? Eur J Cancer. 2016;53:96-104.

36. Tran HT, Liu Y, Zurita AJ, Lin Y, Baker-Neblett KL, Martin $\mathrm{AM}$, et al. Prognostic or predictive plasma cytokines and angiogenic factors for patients treated with pazopanib for metastatic renal-cell cancer: a retrospective analysis of phase 2 and phase 3 trials. Lancet Oncol. 2012;13:827-37.

37. Bianconi M, Faloppi L, Loretelli C, Zizzi A, Bittoni A, Andrikou $\mathrm{K}$, et al. Angiogenesis genotyping in the selection of first-line treatment with either sunitinib or pazopanib for advanced renal cell carcinoma. Oncotarget. 2016;7:37599-607.

38. Xu CF, Bing NX, Ball HA, Rajagopalan D, Sternberg CN, Hutson TE, et al. Pazopanib efficacy in renal cell carcinoma: evidence for predictive genetic markers in angiogenesis-related and exposure-related genes. J Clin Oncol. 2011;29:2557-64.

39. Choueiri TK, Figueroa DJ, Fay AP, Signoretti S, Liu Y, Gagnon $\mathrm{R}$, et al. Correlation of PD-L1 tumor expression and treatment outcomes in patients with renal cell carcinoma receiving sunitinib or pazopanib: results from COMPARZ, a randomized controlled trial. Clin Cancer Res. 2015;21:1071-7.

40. Hahn OM, Yang C, Medved M, Karczmar G, Kistner E, Karrison $\mathrm{T}$, et al. Dynamic contrast-enhanced magnetic resonance imaging pharmacodynamic biomarker study of sorafenib in metastatic renal carcinoma. J Clin Oncol. 2008;26:4572-8.

41. Sweis RF, Medved M, Towey S, Karczmar GS, Oto A, Szmulewitz RZ, et al. Dynamic contrast-enhanced magnetic resonance imaging as a pharmacodynamic biomarker for pazopanib in metastatic renal carcinoma. Clin Genitourin Cancer. 2016. doi:10.1016/j.clgc.2016.08.011.

42. Verheijen RB, Bins S, Mathijssen RHJ, Lolkema MP, van Doorn L, Schellens JHM, et al. Individualized pazopanib dosing: a prospective feasibility study in cancer patients. Clin Cancer Res. 2016;22:5738-46.

43. Heath EI, Infante J, Lewis LD, Luu T, Stephenson J, Tan AR, et al. A randomized, double-blind, placebo-controlled study to evaluate the effect of repeated oral doses of pazopanib on cardiac conduction in patients with solid tumors. Cancer Chemother Pharmacol. 2013;71:565-73.

44. Xu C-F, Johnson T, Wang X, Carpenter C, Graves A, Warren L, et al. HLA-B*57:01 confers susceptibility to pazopanib- associated liver injury in patients with cancer. Clin Cancer Res. 2016;22(6):1371-7.

45. Xu CF, Reck BH, Goodman VL, Xue Z, Huang L, Barnes MR, et al. Association of the hemochromatosis gene with pazopanibinduced transaminase elevation in renal cell carcinoma. J Hepatol. 2011;54:1237-43.

46. Xu CF, Xue Z, Bing N, King KS, Mccann LA, De souza PL, et al. Concomitant use of pazopanib and simvastatin increases the risk of transaminase elevations in patients with cancer. Ann Oncol. 2012;23:2470-1.

47. Vlenterie M, van Erp NP, van der Graaf WT. Promising management of pazopanib-induced liver toxicity. Acta Oncol. 2015;54(7):1-3.

48. Bonate PL, Suttle AB. Modeling tumor growth kinetics after treatment with pazopanib or placebo in patients with renal cell carcinoma. Cancer Chemother Pharmacol. 2013;72:231-40.

49. Ouerdani A, Struemper H, Suttle A, Ouellet D, Ribba B. Preclinical modeling of tumor growth and angiogenesis inhibition to describe pazopanib clinical effects in renal cell carcinoma. CPT Pharmacomet Syst Pharmacol. 2015;4:660-8.

50. Imbs DC, Négrier S, Cassier P, Hollebecque A, Varga A, Blanc E, et al. Pharmacokinetics of pazopanib administered in combination with bevacizumab. Cancer Chemother Pharmacol. 2014;73:1189-96.

51. Yu H, van Erp N, Bins S, Mathijssen RHJ, Schellens JHM, Beijnen $\mathrm{JH}$, et al. Development of a pharmacokinetic model to describe the complex pharmacokinetics of pazopanib in cancer patients. Clin Pharmacokinet. 2016. doi:10.1007/s40262-0160443-y.

52. Eechoute K, Fransson MN, Reyners AK, de Jong F, Sparreboom A, van der Graaf WT, et al. A long-term prospective population pharmacokinetic study on imatinib plasma concentrations in GIST patients. Clin Cancer Res. 2012;18:5780-7.

53. Bins S, Eechoute K, Kloth JSL, de Man FM, Oosten AW, de Bruijn P, et al. Prospective analysis in GIST patients on the role of alpha-1 acid glycoprotein in imatinib exposure. Clin Pharmacokinet. 2016. doi:10.1007/s40262-016-0441-0.

54. Yau T, Chen PJ, Chan P, Curtis CM, Murphy PS, Suttle AB, et al. Phase I dose-finding study of pazopanib in hepatocellular carcinoma: evaluation of early efficacy, pharmacokinetics, and pharmacodynamics. Clin Cancer Res. 2011;17:6914-23.

55. Verheijen RB, Bins S, Thijssen B, Rosing H, Nan L, Schellens $\mathrm{JH}$, et al. Development and clinical validation of an LC-MS/MS method for the quantification of pazopanib in DBS. Bioanalysis. 2016;8:123-34.

56. de Wit D, den Hartigh J, Gelderdblom H, Qian Y, den Hollander $\mathrm{M}$, Verheul H, et al. Dried blood spot analysis for therapeutic drug monitoring of pazopanib. J Clin Pharmacol. 2015;55:1344-50. 